\title{
Long term environmental stability drives reduced stress tolerance in salt lake invertebrates
}

\author{
James E. O'Dwyer', Nicholas P. Murphy' \\ I Dept of Ecology, Environment \& Evolution, La Trobe University, Bundoora, VIC 3086, Melbourne, Australia \\ Corresponding author: James E. O'Dwyer (18088076@students.latrobe.edu.au)
}

Academic editor: G. Brodie | Received 23 September 2020 | Accepted 15 December 2020 | Published 26 February 2021

Citation: O'Dwyer JE, Murphy NP (2021) Long term environmental stability drives reduced stress tolerance in salt lake invertebrates. Rethinking Ecology 6: 49-64. https://doi.org/10.3897/rethinkingecology.6.58899

\begin{abstract}
The capacity of species to tolerate physical stressors is critical in a world of increasing environmental instability, however, past selective environments should dramatically impact on future stress tolerance, particularly in isolated populations. Through stabilising selection, long-term environmental stasis may reduce physiological tolerance, creating an evolutionary legacy where populations are less fit if environments change. Few empirical studies have investigated this evolutionary legacy of past selection, and of particular interest whether stabilising selection in a benign environment reduces stress tolerance in natural systems. Here we use multiple populations of salt-lake invertebrates (Coxiella striata, Austrochiltonia subtenuis) with either stable or fluctuating environmental histories to investigate the relationship between stabilising selection and environmental stress resistance. Tolerance to both salinity and temperature stress were examined in invertebrate populations from lakes with long-term (decadal) stable environments and compared with populations from lakes with extreme salinity variations. Individuals from stable environments demonstrated significantly lower survival under both increasing salinity and temperature stresses when compared with environmentally unstable populations. Our results support the hypothesis that the evolutionary legacy from stabilising selection in constant environments leads to reduced stress tolerance. This finding demonstrates that under an increasingly variable climate, the evolutionary legacies of populations will be critical for future survival and adaptation.
\end{abstract}

\section{Keywords}

Evolutionary legacy, local adaptation, physiological stress tolerance, stabilising selection 


\section{Introduction}

By 2100 over $20 \%$ of environments are predicted to suffer from extreme variability (Williams et al. 2007), and in an increasingly variable climate, it is crucial to understand the adaptation of vulnerable species to changing conditions (IPCC 2014). While there is evidence to show that some species can adapt to widely fluctuating environments, many are predicted to be ill-equipped to handle large scale changes (Thomas et al. 2004). Often the potential to adapt to environments is viewed as a species-level capacity, with populations within a species viewed as contributing equally to overall adaptive potential (Pouget et al. 2016). This perception often overlooks the environmental heterogeneity which often exists across an entire species' range, leading to populations within the same species potentially showing greater or lesser adaptive potential than predicted.

The role that stabilising selection may play in limiting a population's ability to adapt to future change is of particular interest. Stochastic influences, such as population bottlenecks and genetic drift, are well-understood drivers of reduced fitness and phenotypic variation in populations (Fagan and Holmes 2006; Gilpin 1986). However, stabilising selection may also play a role by narrowing the standing variation around a phenotypic optimum (Haller and Hendry 2014; Hendry and Gonzalez 2008), which may reduce adaptability of populations if environmental conditions change. In contrast, an unstable environment with varying selection through time reduces the fitness advantage for any single phenotype through rapidly fluctuating between optimal phenotypes, preventing shifts towards any one phenotypic optimum (Estes et al. 2007; Zhang et al. 2005), and maintaining the range of phenotypes required under changing conditions.

Here, we aim to examine the evolutionary legacy of long-term stabilising selection on the stress tolerance of salt-lake invertebrate populations. Salt-lake systems provide an ideal environment for examining the population-level effects of environmental stability and fluctuation. Firstly, populations of plants and animals in lakes are generally more isolated than those present in interconnected waterways (De Meester et al. 2002), providing the island-like conditions which are ideal for examining evolutionary processes (Grant and Grant 1989). Secondly, the relationship between lake depth and precipitation determine salinity and temperature, in shallow lakes, the water level can fluctuate significantly, leading to short term (often seasonal) changes in salinity and temperature. Populations in shallow lakes must be highly tolerant and adaptable to persist through droughts with increasing salinity and temperature and wetter periods where deeper waters will be less saline and cooler (Dake and Harleman 1969; Wantzen et al. 2008). In contrast, deep lakes are buffered from short-term changes in precipitation and offer long term environmental stability, where populations persist in constant salinity and temperature often for 100s of years (Dake and Harleman 1969; Wantzen et al. 2008).

Here we examine how the fitness of two model species can vary significantly across their range, dependent on a population's environmental history and subsequent evolutionary legacy. In particular, we hypothesise that populations of salt lake invertebrates that have persisted in deep, long-term stable environments have reduced fitness 
under salinity and temperature stress when compared with populations from shallow lakes that experience frequent fluctuating environmental conditions.

\section{Methods}

\section{Study area}

This study investigated populations of salt-lake snail Coxiella striata (Reeve, 1842) and a salt lake amphipod Austrochiltonia subtenuis (Sayce, 1902) found across saline lakes in the Corangamite and Hopkins Basins of western Victoria, Australia (Fig. 1). These lakes were formed by volcanic activity starting in the early Pliocene (Williams 1981) and have been hydrologically isolated from one another for the past 10,000 years since the last major wet phase in the region (Bowler 1981). The lakes have been the location of extensive limnological studies due to their unique fauna (Khan 2003; Leahy 2010; Williams 1981). However, due to a combination of poor land management and extreme drought over the past 40 years, many lakes have been subject to extreme biodiversity loss, and consequently, despite extensive surveys of lakes previously known to contain each species (Leahy 2010), both our target species were only found in four lakes. Two of these lakes are classified as environmentally stable (Lakes Bullen Merri and Struan), and two with significant environmental fluctuations (Lakes Bolac and Bookar) (Fig. 1, Table 1).

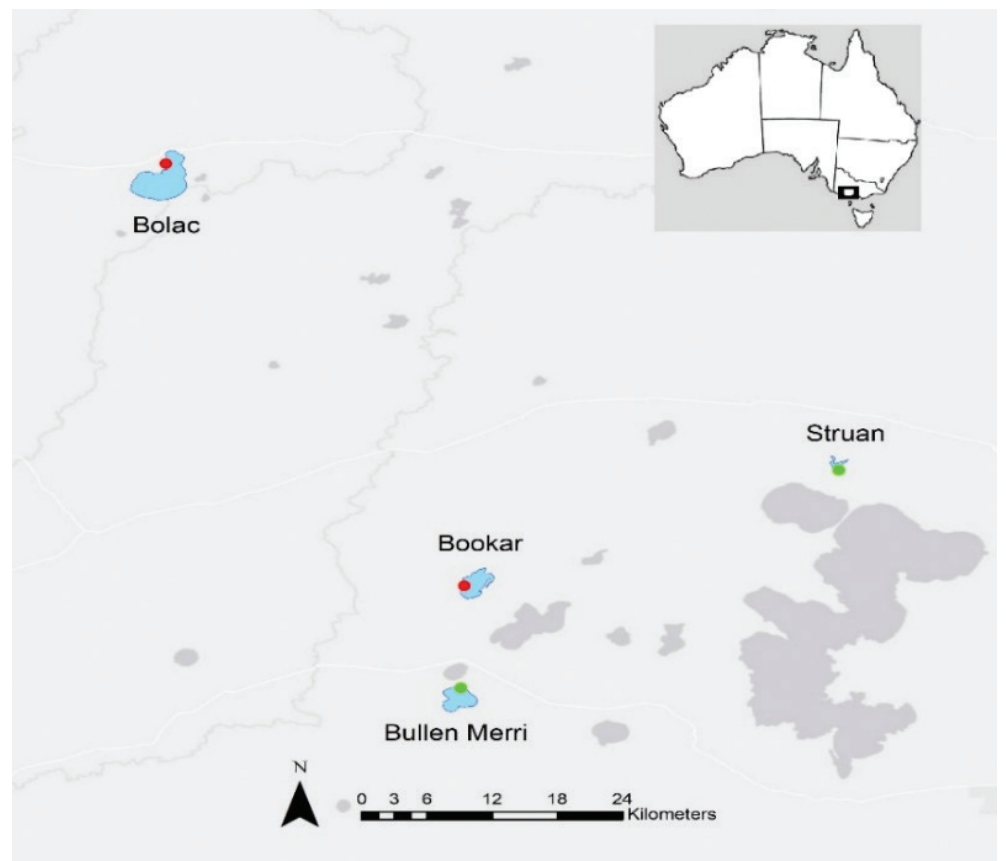

Figure I. Map of sampling locations for each lake. Red circles indicate environmentally unstable lakes; green circles indicate environmentally stable lakes. 
Table I. Locations of each lake, as well as abiotic conditions recorded for each lake and their ecological significance. Temperature, salinity averages, and water level classification data was collected from long term lake monitoring sites (State of Victoria 2017). * As measurements were infrequent previous to 1990 for each lake, standard deviation was calculated from data collected from 1990 to the present.

\begin{tabular}{|c|c|c|c|c|c|c|}
\hline Site & $\begin{array}{l}\text { Latitude/ longitude } \\
\text { coordinates }\end{array}$ & $\begin{array}{c}\text { Salinity (ppt) measured } \\
\text { during the study: } \\
\text { Measurements } 1 / 2\end{array}$ & $\begin{array}{l}\text { 40-year average } \\
\text { salinity (ppt) }\end{array}$ & $\begin{array}{c}\text { Standard deviation } \\
\text { of salinity } \\
\text { measurement* (ppt) }\end{array}$ & \begin{tabular}{|c|}
$\begin{array}{c}\text { Water level } \\
\text { classification }\end{array}$ \\
\end{tabular} & $\begin{array}{c}\text { Temp } \\
\min / \max \\
+ \text { mean }\end{array}$ \\
\hline $\begin{array}{l}\text { Bullen Merri } \\
\text { (stable) }\end{array}$ & $\begin{array}{l}-38.237680, \\
143.105852\end{array}$ & $9.69 / 9.61$ & 8.63 & 0.47 & Deep $(>5 \mathrm{~m})$ & $\begin{array}{c}8 / 27.4 \\
16.5\end{array}$ \\
\hline $\begin{array}{l}\text { Struan } \\
\text { (stable) }\end{array}$ & $\begin{array}{l}-38.019373, \\
143.418475\end{array}$ & $1.94 / 1.96$ & NA & NA & NA & NA \\
\hline $\begin{array}{l}\text { Bolac } \\
\text { (unstable) }\end{array}$ & $\begin{array}{l}-37.720898 \\
142.858117\end{array}$ & $\mathrm{NA} / 4.01$ & 6.27 & 9.60 & $\begin{array}{l}\text { shallow } \\
(<5 \mathrm{~m})\end{array}$ & $\begin{array}{c}8 / 26.6 \\
16.3\end{array}$ \\
\hline $\begin{array}{l}\text { Bookar } \\
\text { (unstable) }\end{array}$ & $\begin{array}{l}-38.145135 \\
143.109618\end{array}$ & $40.19 / 40.32$ & 20.78 & 15.86 & $\begin{array}{l}\text { shallow } \\
(<5 \mathrm{~m})\end{array}$ & $\begin{array}{c}4.7 / 31.2 \\
16.6\end{array}$ \\
\hline
\end{tabular}

Environmental stability and average salinities for Bullen Merri, Bolac, and Bookar were determined from salinity measurements taken over the past 40 years (Suppl. material 1: Additional salinity information from each lake). Both Lakes Bookar (2.5 m deep) and Bolac ( $<5 \mathrm{~m}$ deep) are heavily impacted by evaporation and precipitation and vary considerably in salinity (Leahy 2010). Over the past 20 years, these lakes have ranged from $>80 \mathrm{ppt}$ to $<4 \mathrm{ppt}$, with year to year salinity changes of 10-20 ppt common for both lakes (Suppl. material 1: Additional salinity information from each lake). In contrast, salinity in the $60 \mathrm{~m}$ deep Lake Bullen Merri has remained constant, fluctuating less than $2.5 \mathrm{ppt}$ above or below average (standard deviation $=0.47$ ) over the past 40 years (Table 1). Average salinities for each lake additionally varied, with Bookar being the most saline (20.78 ppt), followed by Bullen Merri (8.63 ppt) and Bolac (6.27 ppt) (Table 1). No long-term salinity data was available for Lake Struan. Unlike Lakes Bookar and Bolac, significant groundwater input (Barton et al. 2006; Thompson 1971) ensures that Lake Struan has maintained a constant water surface area to coastline ratio. This was confirmed from 17 years of aerial photographs, available via Google Earth, which demonstrate lake level stability (and inferred salinity stability) even during the 2001-2009 millennium drought, where neighbouring lakes dried completely (Tweed et al. 2009). Additionally, salinity was measured once for Lake Struan in 1990 returning a salinity of $1.8 \mathrm{ppt}$, nearly identical to the two estimates taken three months apart in 2017 during this study $(1.94,1.96)$ (Table 1) (Gell 1997).

\section{Study species}

The snail C. striata has a wide, non-continuous distribution ranging across South Australia, Western Victoria and Tasmania (Williams and Mellor 1991). Coxiella striata are found in salinities from near brackish to hypersaline and have been shown to have a wide tolerance range for temperature and freshwater exposure (Williams and Mellor 1991).

The amphipod $A$. subtenuis has a wide, non-continuous distribution spanning across South Australia and Victoria (Lim and Williams 1971). Austrochiltonia subtenuis 
shows a similar range of salinity tolerances to $C$. striata, however, has a higher tolerance of hyposalinities, and a lower tolerance to maximum salinity (Lim and Williams 1971).

DNA sequencing was used to determine the taxonomic status and evolutionary independence of each lake population. Snails from each lake were sequenced for two mitochondrial regions, Cytochrome Oxidase I (COI) and 16S ribosomal RNA, as well as the nuclear Internal Transcribed Spacer (ITS) region. Amphipods from each lake were sequenced only for the COI region (Suppl. material 2: Genetics methodology). The results (Suppl. material 2: Genetics methodology) demonstrated that all snail populations belonged to $C$. striata, with evidence that the lakes did not represent a single panmictic population. Similar results were found for the amphipods, where populations were shown to not be panmictic, however, the Lake Bookar population was found to be an unrelated, yet morphologically cryptic species. Therefore, all amphipod samples collected from Lake Bookar were excluded from further analysis.

\section{Stress trials}

Approximately 200 snails and 100 amphipods were collected from each lake for physiological stress testing. Samples were collected using dip nets between one and three metres from the lake shoreline and at a depth between $50 \mathrm{~cm}$ and 1 metre. Salinity and water temperature measurements were taken at the time of collection. Samples from each lake were placed into separate $20 \mathrm{~L}$ aquaria adjusted to the salinity recorded at collection, using Red Sea Salt to approximate major ionic levels found across each lake (Leahy 2010). pH was maintained with API pH increasing solution, and aquaria kept at a 12-hour day-night cycle at $17{ }^{\circ} \mathrm{C}$. Snails and amphipods were fed daily with algae, goldfish flakes, and algal wafers. All samples were acclimatised for 14 days before physical trials commenced. All lake populations were tested simultaneously, with different individuals used for each test, and controls run (each population being kept at the salinity and temperature recorded for that lake upon collection) undertaken with the same handling as each test.

\section{Salinity tolerance trials}

We measured the impact of both gradual salinity change and prolonged salinity exposure on individual survival. To test gradual salinity change, 30 to 40 individuals of either species from each lake were placed into separate plastic bags containing $1 \mathrm{~L}$ of water (within aquaria to maintain temperature). Both increasing and decreasing salinities (from acclimation salinity) were tested; $\mathrm{NaCl}$ was added to increase salinity and fixed volumes of saline water replaced by fresh to decrease salinity. Individual snails were probed daily and observed for a response; non-responsive individuals were placed on their backs and if after five minutes had not righted themselves were considered dead and removed and the salinity recorded. Individual amphipods were considered dead if they had fallen to the bottom of the bag and were not responsive to water currents blown through an eyedropper. 
To test the effect of prolonged salinity exposure, 15 snails from each lake were placed into individual bags at salinity concentrations of $0 \mathrm{ppt}, 40 \mathrm{ppt}, 55 \mathrm{ppt}$, and 70 ppt. Individual death was examined daily, with time of death recorded for each individual. Amphipods were not included in prolonged salinity exposure tests due to insufficient individuals being successfully collected. For all salinity tests, individuals were fed daily and an eyedropper was used to aerate bags daily.

\section{Thermal tolerance trials}

To test thermal tolerance, 30 snails from each lake were placed in separate $1 \mathrm{~L}$ bags under acclimation salinities. Each bag was then placed inside a larger water bath, which underwent a daily temperature increase of $3{ }^{\circ} \mathrm{C}$, starting at $17^{\circ} \mathrm{C}$ until $32^{\circ} \mathrm{C}$, where the temperature was then raised by $1.5^{\circ} \mathrm{C}$ daily. Individual death was examined daily, using the same methods described in the salinity trials.

\section{Data analysis}

For all stress trials, proportional survival rates were measured at each salinity or temperature increment (or each day for the prolonged exposure test). For each trial, a Generalised Linear Model (GLM) was created with "proportion survived" as the dependent variable, and "lake of origin" and "trial condition" as the interacting, independent variables. GLMs were run both with raw data and with a $\log$ transformation of the trial condition. The best fit model for each trial was chosen based on lower Akaike Information Criterion values, allowing for the best model under the conditions tested to be chosen for each dataset (Akaike 1974). The overall fit of the data with each model was then calculated as the $\mathrm{D}^{2}$ value of the model ((null deviance - deviance)/null deviance), and the model was used to generate mean predicted values and confidence intervals around each data point for each lake, using the R package boot v 1.3 (Davison and Hinkley 1997). For models which required log transformation of trial condition, all condition values of 0 were changed to 0.1 to allow for a log transformation of the data. The results obtained for each trial were plotted alongside the generated confidence intervals using the R package ggplot2 $\mathrm{v}$ 3.2.0 (Wickham 2016), and significant differences between proportion survived from each lake under each condition inferred through non-overlapping confidence intervals $(\mathrm{p}<0.05)$.

\section{Results}

\section{Controls}

Throughout the entire testing period, the controls of the snail species $C$. striata showed a decline of less than $10 \%$ for each population (Suppl. material 3: Control trials). The controls of the amphipod $A$. subtenuis showed a decline of approximately $30-40 \%$ (Suppl. material 3). 


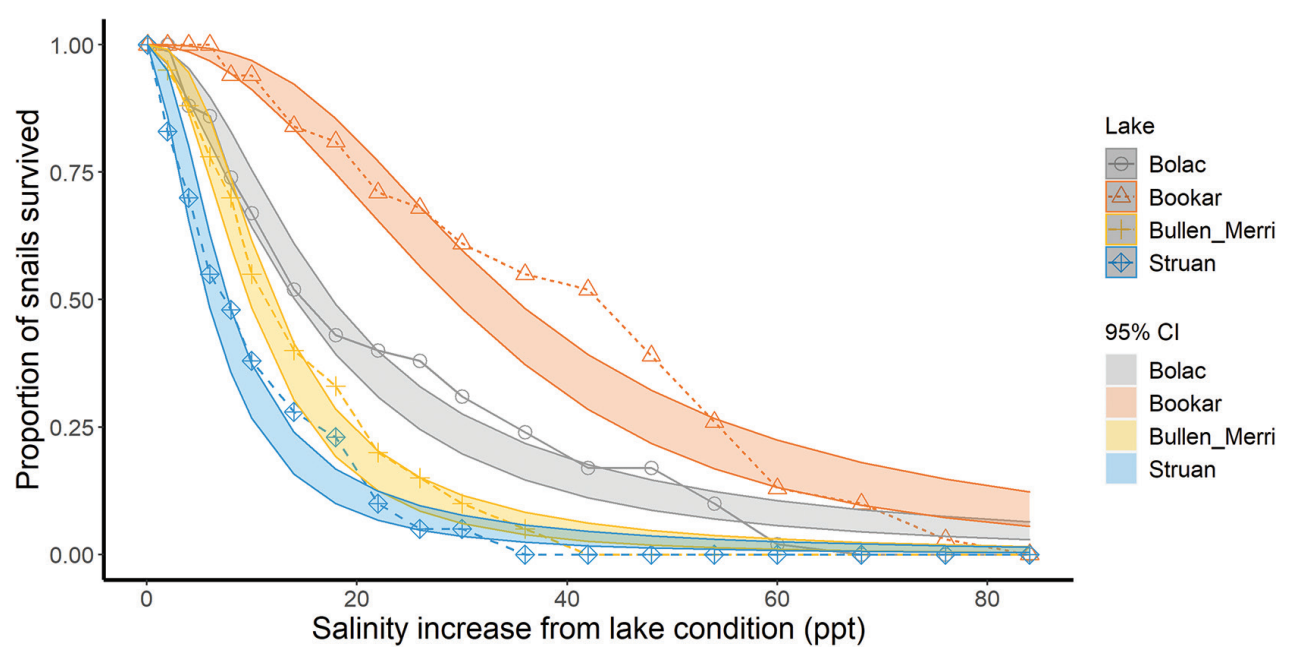

Figure 2. Survival rate under gradually increasing salinity for populations of $C$. striata snails from each lake. Shaded areas are representative of a $95 \%$ confidence interval for proportion of living snails under each predicted mean. $\mathrm{D}^{2}$ of the model is 0.9594 . Additional statistics for each model can be found in Suppl. material 4.

\section{Salinity trials}

All populations from both species displayed responses to increasing salinity exposure in line with initial predictions. Snails from fluctuating environments (Lakes Bookar and Bolac) displaying greater tolerance to stress (Fig. 2). No snails from Bullen Merri or Struan survived a salinity increase $>35 \mathrm{ppt}$, whilst both Bookar and Bolac snails demonstrated $>10 \%$ survival after salinity was increased $>60$ ppt. Bookar snails, which experienced the highest salinity upon collection, demonstrated the greatest survival, however, the relationship between collection salinity and survival does not hold for Lake Bolac, which were collected at half the salinity of the stable Bullen Merri population, yet had much higher survival in increasing salinity. Like the snails, the amphipods taken from both stable lakes, Struan and Bullen Merri, showed a significantly decreased survival rate when compared to the population from Bolac (Fig. 3). This is most clearly seen at an increase in salinity of $30 \mathrm{ppt}$, with the survival of Bolac amphipods, $-75 \%$ compared with compared $<25 \%$ in Bullen Merri and Struan.

The prolonged exposure to increased salinity (measured only in the snail populations) reflects those of the gradual salinity increase. Again, the stable lakes, Bullen Merri and Struan, were the most vulnerable (Fig. 4A), with $<25 \%$ survival after 5 days, and $0 \%$ survival upon conclusion of the $40 \mathrm{ppt}$ test. In contrast, survival after 5 days is significantly higher in Bookar (100\%, 40 ppt being the control salinity for Bookar), and to a lesser extent Bolac (50\%), with snails from both fluctuating lakes persisting in $40 \mathrm{ppt}$ for the extent of the trial (Fig. 4A). By day 9 of the $55 \mathrm{ppt}$ trial, no individuals from either Lakes Bullen Merri or Struan had survived while 35\% of individuals from Lake Bolac and 75\% from Lake Bookar remained (Fig. 4B). Only the Lake Bookar population had individuals who survived 15 days in 70 ppt (Fig. 4C). 


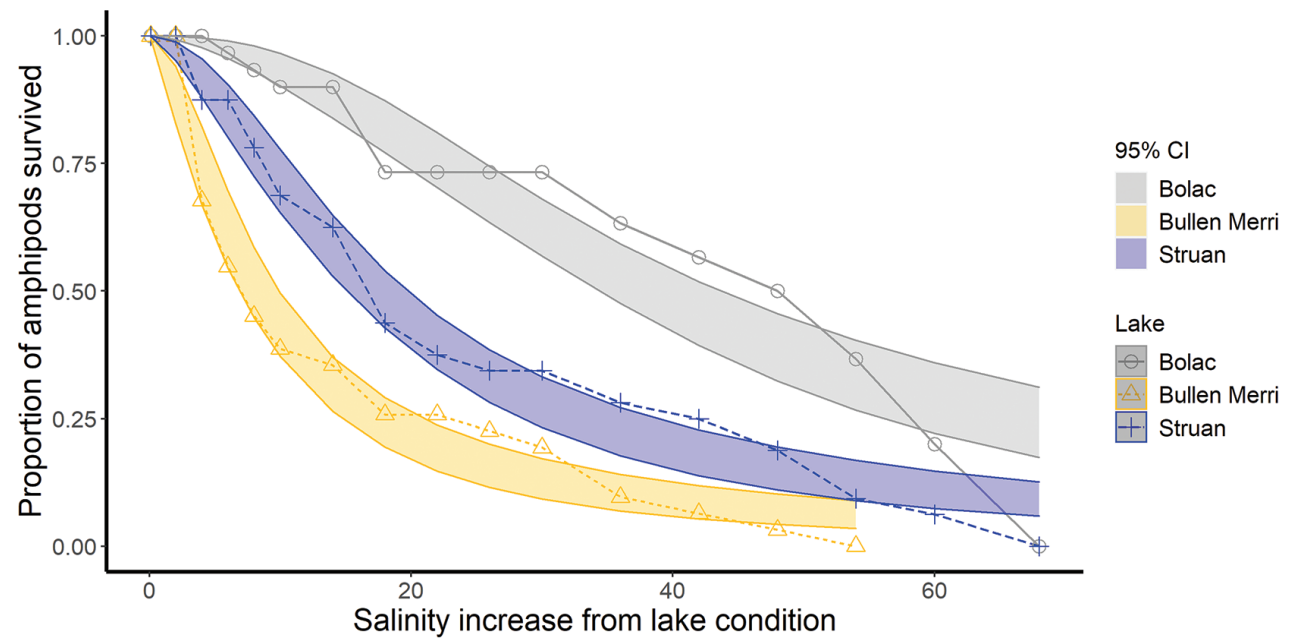

Figure 3. Survival rate under gradually increasing salinity for populations of $A$. subtenuis from each lake. Shaded areas are representative of a $95 \%$ confidence interval for proportion of living amphipods under each predicted mean. The $\mathrm{D}^{2}$ of the model is 0.9315 . Additional statistics for each model can be found in Suppl. material 4.
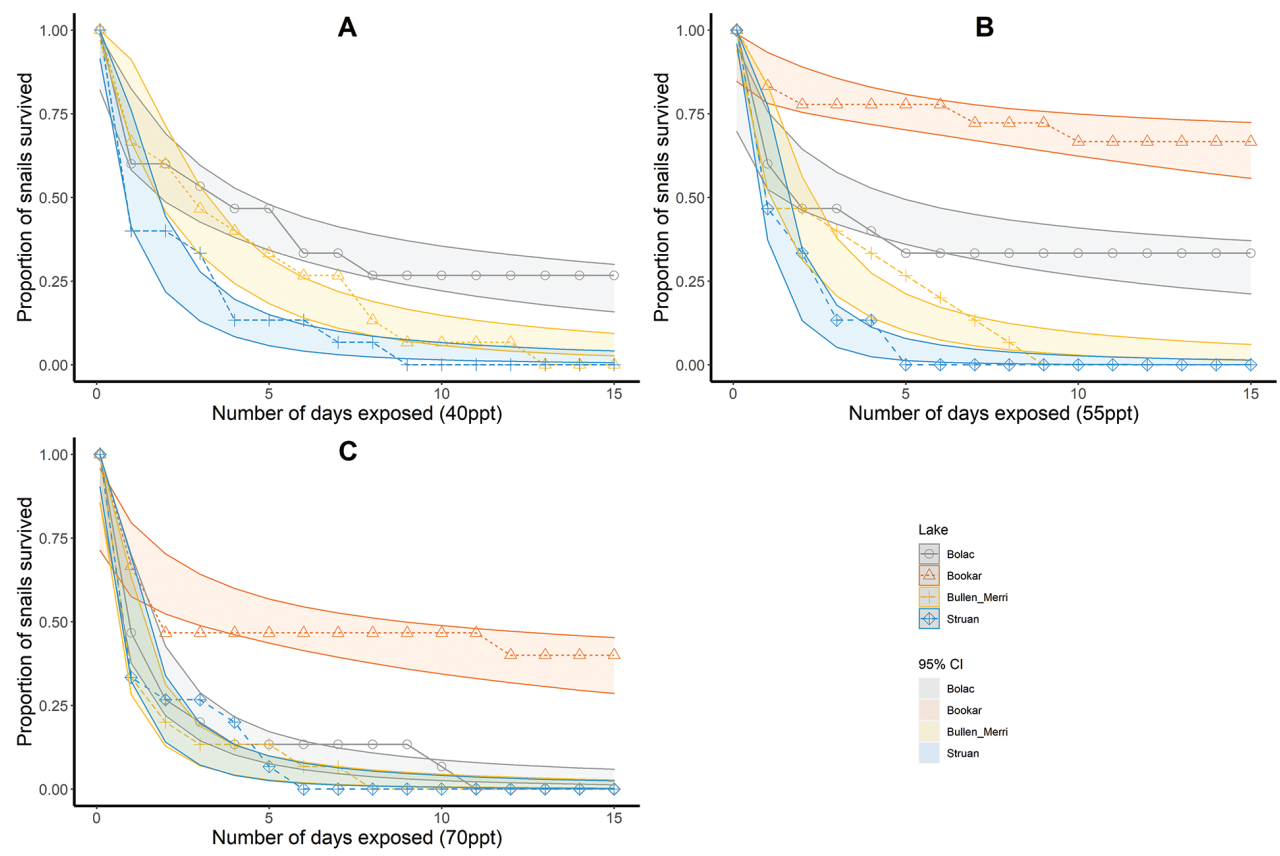

Figure 4. Survival rate plotted against days exposure to conditions of $40 \mathrm{ppt}(\mathbf{A}), 55 \mathrm{ppt}(\mathbf{B})$, and $70 \mathrm{ppt}$ (C) for populations of C. striata from each lake. Shaded areas are representative of a $95 \%$ confidence interval for proportion of living snails under each predicted mean. The $\mathrm{D}^{2}$ of the $40 \mathrm{ppt}, 55 \mathrm{ppt}$, and $70 \mathrm{ppt}$ models are $0.9115,0.9165$, and 0.9159 respectively. Additional statistics for each model can be found in Suppl. material 4. 


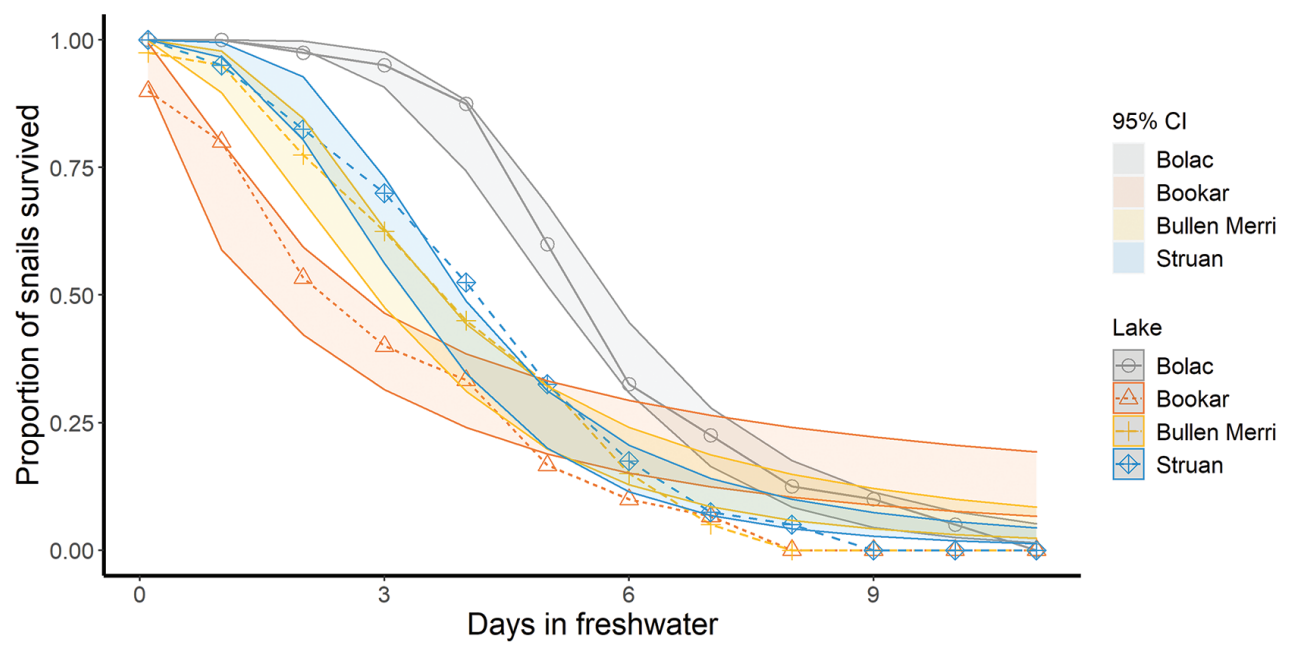

Figure 5. Survival rate under the number of days of exposure to freshwater for populations of C. striata from each lake. Shaded areas are representative of a $95 \%$ confidence interval for proportion of living snails under each predicted mean. $\mathrm{D}^{2}$ of the model is 0.9457 . Additional statistics for each model can be found in Suppl. material 4.

\section{Freshwater exposure trials}

Prolonged exposure to freshwater demonstrated contrasting relationships amongst populations (Figs 5, 6). Both Bolac snails and amphipods were the most tolerant of freshwater conditions. For the snail populations the stable lakes, Struan and Bullen Merri, had reduced survival in freshwater, whilst Bookar populations demonstrated significantly lower survival ( $>70 \%$ by day 2 of the tests). However by day 10 , all snail populations had succumbed to the freshwater conditions.

\section{Temperature trials}

The temperature trials (only undertaken on snails) reflected the results of the salinity testing, with Bookar the most tolerant to increasing temperature followed by Bolac, whilst Bullen Merri and Struan are less tolerant to temperature increase. There were significant differences between all lakes once temperatures became $>36.5^{\circ} \mathrm{C}$. At this temperature, there was $0 \%$ survival from Bullen Merri and Struan snails, whilst survival in both Bookar and Bolac was $>10 \%$ in temperatures $>38^{\circ} \mathrm{C}$ (Fig. 7).

\section{Discussion}

The selection processes that limit phenotypic diversity have crucial implications for the survival of populations in a changing world (Norberg et al. 2001). This study 


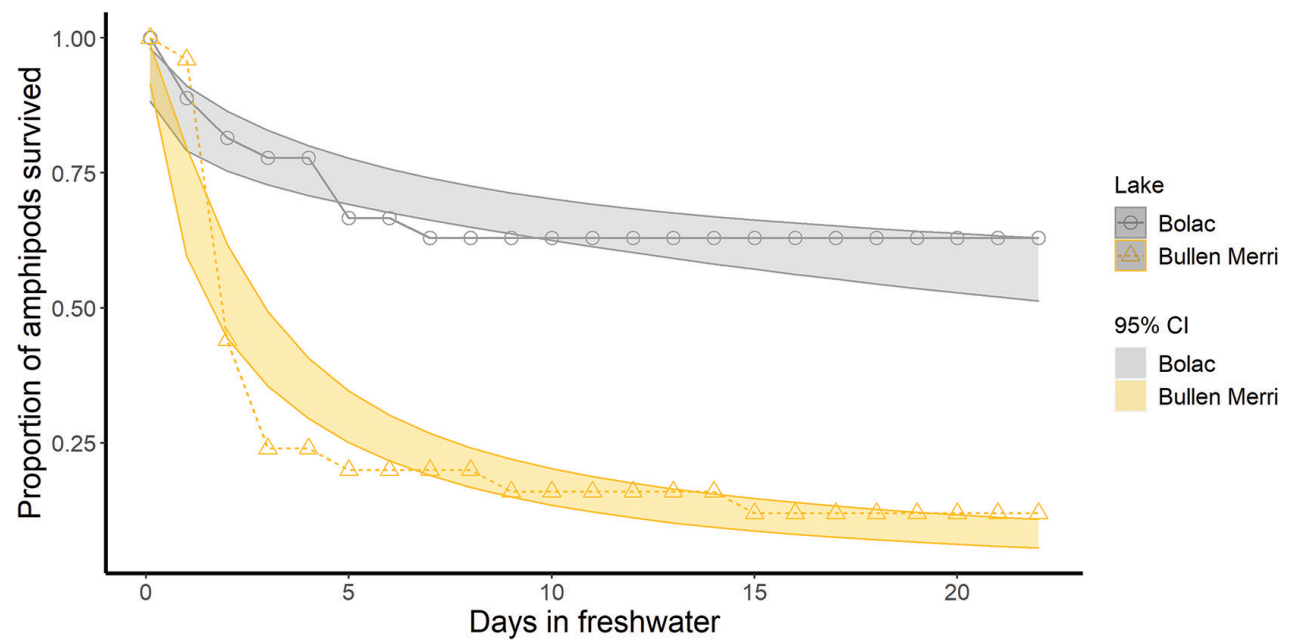

Figure 6. Survival rate under the number of days of exposure to freshwater for populations of $A$. subtenuis from each lake and controls. Shaded areas are representative of a $95 \%$ confidence interval for proportion of living amphipods under each predicted mean. $\mathrm{D}^{2}$ of the model is 0.9326 . Additional statistics for each model can be found in Suppl. material 4.

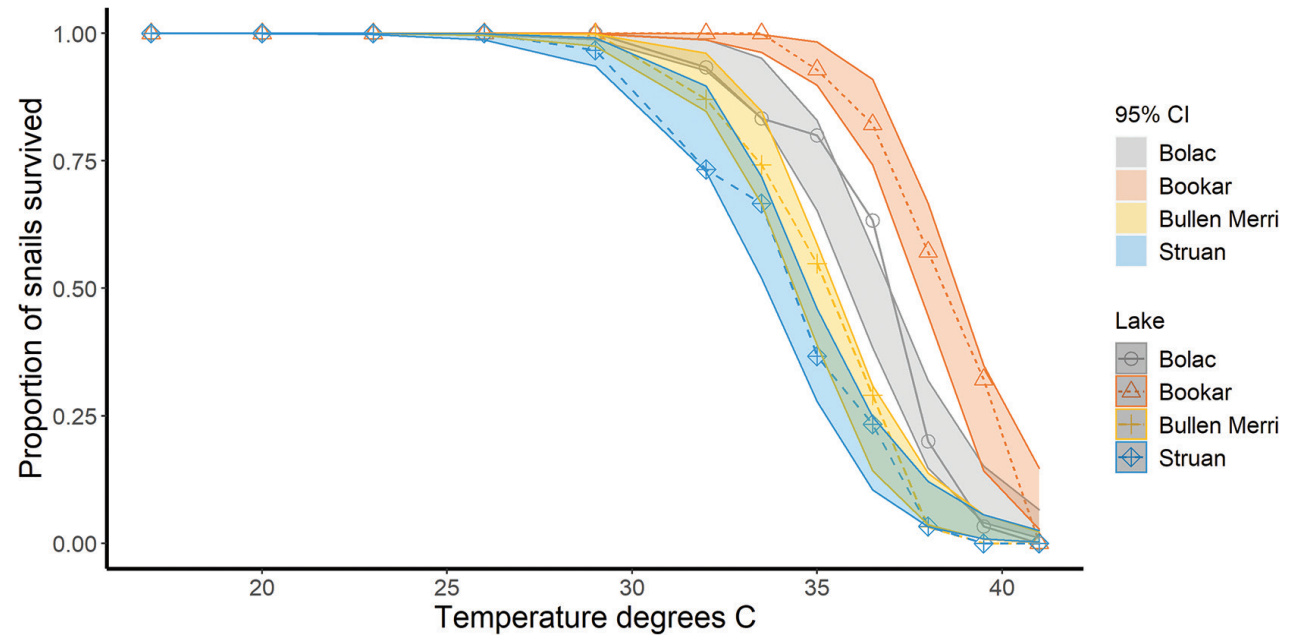

Figure 7. Survival rate under gradually increasing temperatures for populations of $C$. striata from each lake. Shaded areas are representative of a $95 \%$ confidence interval for proportion of living snails under each predicted mean. $\mathrm{D}^{2}$ of the model is 0.9758 . Additional statistics for each model can be found in Suppl. material 4.

provides preliminary evidence that the evolutionary legacy of environmental stability across multiple generations, can act to reduce the stress tolerance in a natural population. Our results suggest that stabilising selection plays an important role in restricting population-level phenotypic variance. Alternatively, our results of increased survival under stress, in populations that had historically endured large environmental variation, reaffirm the strength of fluctuating selection in maintaining standing variation within populations. 
While previous studies have found evidence of environmental histories driving stress response at a species level (Kellermann et al. 2006, 2009) our results provide evidence that different environmental histories lead to significant phenotypic variation within species, amongst populations. Higher survival rates in lakes which experienced significant environmental fluctuation over many years suggest that higher stress tolerances may be present throughout unstable populations (Kussell and Leibler 2005). In contrast, the reduction in stress tolerance in lakes that have experienced little environmental change over decades fits the theoretical implications of stabilising selection (Estes et al. 2007). Critically, here we have demonstrated that these patterns are present in two completely unrelated species; this points to a general influence of stabilising selection within salt lake ecosystems as a whole and warrants further study. Further, our results suggest that the influence of stabilising selection on reducing stress tolerance should be examined in populations that inhabit other historically-stable environments such as long unburnt forests (Newbery and Lingenfelder 2017) or groundwater-dependent ecosystems (Gibert and Deharveng 2002).

Acclimation effects are also important to consider here (Tomanek and Somero 1999), for instance, the Lake Bookar populations demonstrate both the highest salinity at collection and greatest tolerance to high salinities and had the lowest tolerance to freshwater conditions. Other findings, however, are poorly explained by acclimation, instead supporting the theory of evolutionary legacy. Acclimation cannot explain the Lake Bolac results, which in the past 20 years has endured both high and low salinities, had a salinity of near freshwater at the time of collection ( $4 \mathrm{ppt}$ ), yet both snails and amphipods from this lake demonstrated significantly higher survival in increased salinity than either of the stable lakes, despite Bullen Merri displaying a collection salinity over twice as high as Lake Bolac (9.6 ppt). In addition, the results of the temperature stress trials fit the hypothesised results for greater tolerance in unstable populations, despite uniform temperature upon sample collection.

Another factor to consider is the role dispersal may play in mitigating any potential phenotypic shifts in stress tolerances within populations of each lake. The genetic analyses of each species demonstrated private haplotypes within each lake population, and significant pairwise $\mathrm{F}_{\mathrm{ST}}$ between, suggesting population isolation (Slatkin 1985). However, more research is required to better understand the role that dispersal may play in evolution of tolerance in these lakes. Given the strong differences demonstrated in this study, we suggest that a high level of contemporary gene flow would be required to reintroduce phenotypes lost as a result of stabilising selection. However, to better understand the degree of isolation, or the role of population connectivity, and to determine the relative strength of locally adaptive differences, a more comprehensive analysis of gene flow and dispersal is required.

Here we stress that these results are preliminary and that relative impacts of evolutionary legacy should be examined over multiple generations, and ideally from additional populations. However, the key findings from this study strongly support that heritable stress resistances, driven by historic lake conditions, contribute significantly to the tolerance differences amongst populations. The salinity tolerances of the unstable populations are far above their present-day conditions, but clearly, high tolerance is 
not a species-wide trait in both snails and amphipods. Critically, the evolutionary legacy of low-stress tolerance driven by environmental stability could lead to populations being unable to survive minor environmental changes. There are, however, key limitations within this study which must be considered when understanding the broader implications of the impact of evolutionary legacy seen here. We acknowledge that the presence of only four total lake populations precludes a definitive assertion about the importance of evolutionary legacy. Instead, in writing this work, we hope to provide preliminary evidence of the underestimated impact of stabilising selection and argue that further work is critical to explore the true extent of this phenomenon. We suggest that much more research on empirical examples of species inhabiting both stable and fluctuating environments is required, especially in isolated populations where natural evolutionary rescue may take multiple generations.

Our results demonstrate that environmental history could be used to gauge the likely evolutionary limits of populations and therefore could be used to better identify better sources for promoting phenotypic variation (Watters et al. 2003). For instance, this information could be used to facilitate evolutionary restoration, effectively complementing the goals of genetic rescue programs (Hedrick 2005). This is directly applicable to the salt lakes studied in this system, where despite their RAMSAR listing, many local extinctions have occurred due to environmental change in the past 50 years, and more are predicted in the future. For instance, salinity in Lake Bullen Merri is predicted to more than double as a result of climate change (Kirono et al. 2009), and the current population of snails and amphipods will likely need supplementing with tolerant phenotypes to survive.

With many habitats predicted to become increasingly prone to larger environmental fluctuations under an increasingly variable climate (IPCC 2014), the findings of this study may have direct implications for ongoing conservation practices, where often the goal is to maintain environmental stability. Under this increasingly variable climate, many populations may be far less equipped to deal with environmental fluctuations than previously thought. There is an excellent body of theoretical and controlled laboratory research that supports the role of evolutionary legacies (Estes et al. 2007; Zhang et al. 2005). There is now a need for more simple empirical examples, such as shown in this study, to ensure that evolutionary thinking is better incorporated into species management. In particular, we believe that our results demonstrate the under-estimated role that long-term stabilising selection can play in narrowing the ability for species to cope with future change, and that population-level variability in stress tolerance must be considered.

\section{Acknowledgements}

We would like to thank the Murray Darling Freshwater Research Centre for assistance in funding this study. We would also like to thank Simon Watson for assistance with data analysis, and Erin Hill, Jude Hatley, Katherine Harrisson, and Joshua Grubb 
for their assistance with laboratory protocols and feedback on manuscripts. Lastly, we would like to thank all fieldwork volunteers who assisted with the collection of samples. The authors declare no conflict of interest.

\section{References}

Akaike H (1974) A new look at the statistical model identification. IEEE transactions on automatic control 19: 716-723. https://doi.org/10.1109/TAC.1974.1100705

Barton A, Herczeg A, Cox J, Dahlhaus P (2006) Sampling and analysis of lakes in the Corangamite CMA region. CSIRO Land and Water Science Report 34: 06-12.

Bowler J (1981) Australian salt lakes. Hydrobiologia 81: 431-444. https://doi.org/10.1007/ BF00048730

Dake JM, Harleman DR (1969) Thermal stratification in lakes: analytical and laboratory studies. Water resources research 5: 484-495. https://doi.org/10.1029/WR005i002p00484

Davison AC, Hinkley DV (1997) Bootstrap Methods and Their Applications. Cambridge University Press, Cambridge, 582 pp. https://doi.org/10.1017/CBO9780511802843

De Meester L, Gómez A, Okamura B, Schwenk K (2002) The Monopolization Hypothesis and the dispersal-gene flow paradox in aquatic organisms. Acta Oecologica 23: 121-135. https://doi.org/10.1016/S1146-609X(02)01145-1

Estes S, Arnold S, Xa J, Blows MW, Geber MA (2007) Resolving the Paradox of Stasis: Models with Stabilizing Selection Explain Evolutionary Divergence on All Timescales. The American Naturalist 169: 227-244. https://doi.org/10.1086/510633

Fagan WF, Holmes EE (2006) Quantifying the extinction vortex. Ecology Letters 9: 51-60. https://doi.org/10.1111/j.1461-0248.2005.00845.x

Gell PA (1997) The Development of a Diatom Database for Inferring Lake Salinity, Western Victoria, Australia: Towards a Quantitative Approach for Reconstructing Past Climates. Australian Journal of Botany 45: 389-423. https://doi.org/10.1071/BT96036

Gibert J, Deharveng L (2002) Subterranean Ecosystems: A Truncated Functional Biodiversity: This article emphasizes the truncated nature of subterranean biodiversity at both the bottom (no primary producers) and the top (very few strict predators) of food webs and discusses the implications of this truncation both from functional and evolutionary perspectives. BioScience 52(6): 473-481. https://doi.org/10.1641/0006-3568(2002)052[0473:SEATFB]2.0.CO;2

Gilpin M (1986) Minimum viable populations: Processes of extinction in ME Soulé editor. Conservation Biology: The Science of Scarcity and Diversity Sinauer Associates, Sunderland.

Grant BR, Grant PR (1989) Evolutionary dynamics of a natural population: the large cactus finch of the Galápagos. University of Chicago Press.

Haller BC, Hendry AP (2014) Solving the paradox of stasis: Squashed stabilizing selection and the limits of detection. Evolution 68: 483-500. https://doi.org/10.1111/evo.12275

Hedrick P (2005) 'Genetic restoration:' a more comprehensive perspective than 'genetic rescue'. Trends in Ecology \& Evolution 20(3): 109-109. https://doi.org/10.1016/j.tree.2005.01.006 Hendry AP, Gonzalez A (2008) Whither adaptation? Biology \& Philosophy 23: e673. https:// doi.org/10.1007/s10539-008-9126-x 
IPCC (2014) Climate Change 2014: Synthesis Report. Contribution of Working Groups I, II and III to the Fifth Assessment Report of the Intergovernmental Panel on Climate Change. Geneva, Switzerland.

Kellermann VM, van Heerwaarden B, Hoffmann AA, Sgro CM (2006) Very low additive genetic variance and evolutionary potential in multiple populations of two rainforest Drosophila species. Evolution 60: 1104-1108. https://doi.org/10.1554/05-710.1

Kellermann VM, van Heerwaarden B, Sgro CM, Hoffmann AA (2009) Fundamental evolutionary limits in ecological traits drive Drosophila species distributions. Science 325: 1244-1246. https://doi.org/10.1126/science.1175443

Khan TA (2003) Limnology of four saline lakes in western Victoria, Australia. Limnologica Ecology and Management of Inland Waters 33: 327-339. https://doi.org/10.1016/S00759511(03)80027-0

Kirono DG, Jones RN, Kent DM (2009) Modelling future lake levels and salinity at three lakes, Western Victoria. National Research Flagships, Climate Adaptation CSIRO - A report prepared for the Environment Protection Authority (EPA) Victoria.

Kussell E, Leibler S (2005) Phenotypic Diversity, Population Growth, and Information in Fluctuating Environments. Science 309: 2075-2078. https://doi.org/10.1126/science.1114383

Leahy P, Robinson D, Patten R, Kramer A (2010) Lakes in the western district of Victoria and climate change. Environmental Protection Agency Victoria, Carlton.

Lim KH, Williams WD (1971) Ecology of Austrochiltonia subtenuis (Sayce) (Amphipoda, Hyalellidae). Crustaceana 20: 19-24. https://doi.org/10.1163/156854071X00490

Newbery DM, Lingenfelder M (2017) Progression and stability analysis of rain forest tree growth under environmental stochasticity. Ecosphere 8: e01813. https://doi.org/10.1002/ecs2.1813

Norberg J, Swaney DP, Dushoff J, Lin J, Casagrandi R, Levin SA (2001) Phenotypic diversity and ecosystem functioning in changing environments: A theoretical framework. Proceedings of the National Academy of Sciences 98: 11376-11381. https://doi.org/10.1073/pnas.171315998

Pouget M, Youssef S, Dumas PJ, Baumberger T, San Roman A, Torre F, Affre L, Médail F, Baumel A (2016) Spatial mismatches between plant biodiversity facets and evolutionary legacy in the vicinity of a major Mediterranean city. Ecological Indicators 60: 736-745. https://doi.org/10.1016/j.ecolind.2015.07.017

Slatkin M (1985) Rare Alleles as Indicators of Gene Flow. Evolution 39: 53-65. https://doi. org/10.2307/2408516

State of Victoria (2017) Water measurement information.

Thomas CD, Cameron A, Green RE, Bakkenes M, Beaumont LJ, Collingham YC, Erasmus BFN, de Siqueira MF, Grainger A, Hannah L, Hughes L, Huntley B, van Jaarsveld AS, Midgley GF, Miles L, Ortega-Huerta MA, Townsend Peterson A, Phillips OL, Williams SE (2004) Extinction risk from climate change. Nature 427: 145-148. https://doi. org/10.1038/nature02121

Thompson BR (1971) The geology and hydrogeology of the Corangamite region (Masters of Science). The University of Melbourne.

Tomanek L, Somero GN (1999) Evolutionary and acclimation-induced variation in the heatshock responses of congeneric marine snails (genus Tegula) from different thermal habitats: implications for limits of thermotolerance and biogeography. The Journal of Experimental Biology 202: 2925-2936. https://doi.org/10.1016/S1095-6433(99)90421-X 
Tweed S, Leblanc M, Cartwright I (2009) Groundwater-surface water interaction and the impact of a multi-year drought on lakes conditions in South-East Australia. Journal of Hydrology 379: 41-53. https://doi.org/10.1016/j.jhydrol.2009.09.043

Wantzen KM, Rothhaupt K-O, Mörtl M, Cantonati M, László G, Fischer P (2008) Ecological effects of water-level fluctuations in lakes: an urgent issue. Ecological effects of water-level fluctuations in lakes. Springer, 4 pp. https://doi.org/10.1007/978-1-4020-9192-6_1

Watters JV, Lema SC, Nevitt GA (2003) Phenotype management: a new approach to habitat restoration. Biological Conservation 112: 435-445. https://doi.org/10.1016/S00063207(02)00343-9

Wickham H (2016) ggplot2: elegant graphics for data analysis. Springer, Cham, 260 pp. https://doi.org/10.1007/978-3-319-24277-4

Williams JW, Jackson ST, Kutzbach JE (2007) Projected distributions of novel and disappearing climates by 2100 AD. Proceedings of the National Academy of Sciences 104: 5738574. https://doi.org/10.1073/pnas.0606292104

Williams WD (1981) The limnology of saline lakes in Western Victoria. Hydrobiologia 81: 233-259. https://doi.org/10.1007/BF00048719

Williams WD, Mellor MW (1991) Ecology of Coxiella (Mollusca, Gastropoda, Prosobranchia), a snail endemic to Australian salt lakes. Palaeogeography, Palaeoclimatology, Palaeoecology 84: 339-355. https://doi.org/10.1016/0031-0182(91)90053-T

Zhang X-S, Hill WG, Bjorklund M (2005) Evolution of the environmental component of the phenotypic variance: Stabilizing selection in changing environments and the cost of homogeneity. Evolution 59: 1237-1244. https://doi.org/10.1554/05-038

\section{Supplementary material I}

\section{Additional salinity information from each lake}

Authors: James E. O'Dwyer, Nicholas P. Murphy

Data type: Environmental variables

Explanation note: This file contains additional information of salinity for each of the studied salt lakes.

Copyright notice: This dataset is made available under the Open Database License (http://opendatacommons.org/licenses/odbl/1.0/). The Open Database License $(\mathrm{ODbL})$ is a license agreement intended to allow users to freely share, modify, and use this Dataset while maintaining this same freedom for others, provided that the original source and author(s) are credited.

Link: https://doi.org/10.3897/rethinkingecology.6.58899.suppl1 


\section{Supplementary material 2}

\section{Population genetic analysis}

Authors: James E. O'Dwyer, Nicholas P. Murphy

Data type: phylogenetics

Explanation note: This file contains the methods and results of the genetic analysis undertaken to confirm population isolation and the same species were being examined.

Copyright notice: This dataset is made available under the Open Database License (http://opendatacommons.org/licenses/odbl/1.0/). The Open Database License $(\mathrm{ODbL})$ is a license agreement intended to allow users to freely share, modify, and use this Dataset while maintaining this same freedom for others, provided that the original source and author(s) are credited.

Link: https://doi.org/10.3897/rethinkingecology.6.58899.suppl2

\section{Supplementary material 3}

\section{Control trials of each species}

Authors: James E. O'Dwyer, Nicholas P. Murphy

Data type: Control trials

Explanation note: This file contains information on the results of control trials for each species.

Copyright notice: This dataset is made available under the Open Database License (http://opendatacommons.org/licenses/odbl/1.0/). The Open Database License $(\mathrm{ODbL})$ is a license agreement intended to allow users to freely share, modify, and use this Dataset while maintaining this same freedom for others, provided that the original source and author(s) are credited.

Link: https://doi.org/10.3897/rethinkingecology.6.58899.suppl3

\section{Supplementary material 4}

\section{Additional information on model coefficients and significance}

Authors: James E. O'Dwyer, Nicholas P. Murphy

Data type: statistical information

Explanation note: This document contains information on the coefficients, Null and residual deviance and analysis of devience for each of the generalised linear models generated within this study.

Copyright notice: This dataset is made available under the Open Database License (http://opendatacommons.org/licenses/odbl/1.0/). The Open Database License $(\mathrm{ODbL})$ is a license agreement intended to allow users to freely share, modify, and use this Dataset while maintaining this same freedom for others, provided that the original source and author(s) are credited.

Link: https://doi.org/10.3897/rethinkingecology.6.58899.suppl4 